\title{
Classification and clinical behavior of blastic plasmacytoid dendritic cell neoplasms according to their maturation- associated immunophenotypic profile
}

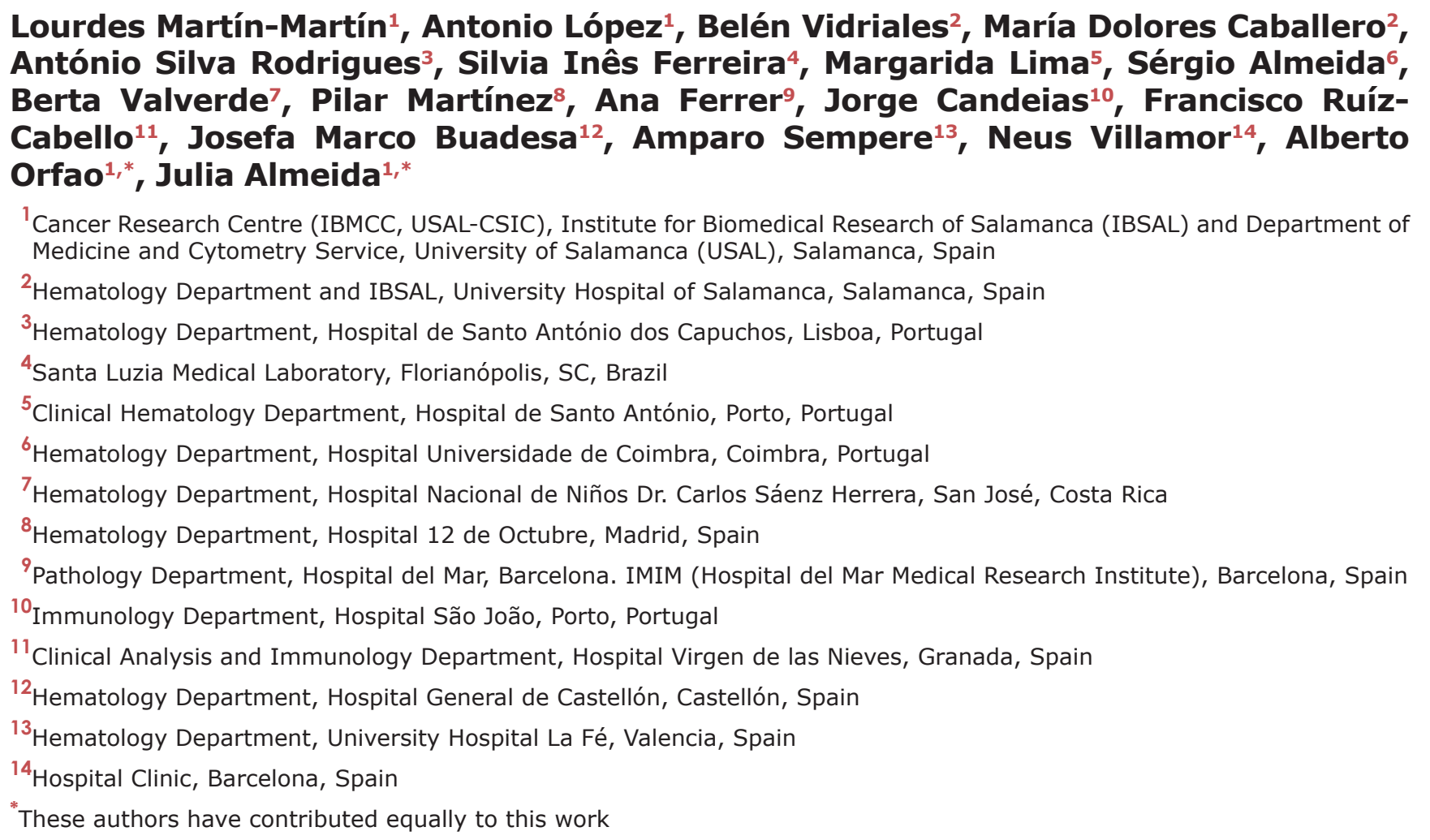

Correspondence to:

Alberto Orfao, e-mail: orfao@usal.es

Keywords: blastic plasmacytoid dendritic cell neoplasm, flow cytometry, maturation profile, acute leukemia, lymphoma Received: April 15, 2015

Accepted: May 11, 2015

Published: May 25, 2015

\section{ABSTRACT}

Blastic plasmacytoid dendritic cell neoplasm (BPDCN) is a rare subtype of leukemia/lymphoma, whose diagnosis can be difficult to achieve due to its clinical and biological heterogeneity, as well as its overlapping features with other hematologic malignancies. In this study we investigated whether the association between the maturational stage of tumor cells and the clinico-biological and prognostic features of the disease, based on the analysis of 46 BPDCN cases classified into three maturationassociated subgroups on immunophenotypic grounds. Our results show that blasts from cases with an immature plasmacytoid dendritic cell (PDC) phenotype exhibit an uncommon CD56- ${ }^{-}$henotype, coexisting with CD34+ non-pDC tumor cells, typically in the absence of extramedullary (e.g. skin) disease at presentation. Conversely, patients with a more mature blast cell phenotype more frequently displayed skin/ extramedullary involvement and spread into secondary lymphoid tissues. Despite the dismal outcome, acute lymphoblastic leukemia-type therapy (with central nervous system prophylaxis) and/or allogeneic stem cell transplantation appeared to be the only effective therapies. Overall, our findings indicate that the maturational profile 


\section{of pDC blasts in BPDCN is highly heterogeneous and translates into a wide clinical spectrum -from acute leukemia to mature lymphoma-like behavior-, which may also lead to variable diagnosis and treatment.}

\section{INTRODUCTION}

Blastic plasmacytoid dendritic cell neoplasm (BPDCN) is a relatively rare subtype of leukemia/ lymphoma $-<1 \%$ of hematologic malignancies [1]- which has been recently categorized in the 2008 World Health Organization (WHO) classification of hematological diseases [2] under acute myeloid leukemia (AML) and related precursor neoplasms. Accumulating evidences show that the normal cellular counterpart of BPDCN resides in the plasmacytoid dendritic cell $(\mathrm{pDC})$ lineage [3]. Despite all the above, diagnosis of BPDCN still remains a challenge; this is probably due to several reasons including its overlapping features with other entities, the lack of recurrent and specific chromosomal abnormalities [4, 5], and its heterogeneous clinical presentation with multiple and variable tissue localizations [6-8]. In addition, diagnosis of BPDCN can be difficult to achieve, particularly when blast cells do not completely fit the typical $\mathrm{CD} 4^{+} \mathrm{CD} 56^{+} \mathrm{HLA}^{-\mathrm{DR}}{ }^{\mathrm{hi}} \mathrm{CD} 123^{+}$lineage (Lin) $)^{-}$immunophenotypic profile $[6,9]$. In fact, at present it is now well-established that tumor cells from BPDCN do express markers which have been classically related to other cell lineages such as CD33, TdT, CD79a, CD2 and CD7 [10, 11], and evidences exist about a broad range of atypical phenotypic profiles in a substantial proportion of cases (up to more than one third of cases), including absence of CD56 [12] and CD4 [13]. Such heterogeneity is also observed at the genetic and molecular level, since multiple and diverse, but unspecific, chromosomal and molecular alterations have been identified $[4,5]$ with even mutually exclusive gene mutations [14]. Therefore, BPDCN are not only clinically heterogeneous but they also show a considerable biologic diversity which in some cases makes diagnosis difficult. This, together with the low prevalence of the disease, has hampered the study of large series of patients, with few exceptions $[6,7,15]$, most reports on BPDCN being based on single or just a few cases. Besides, some of the few larger series reported so far are biased, as they generally include only cases showing cutaneous involvement in the absence of systemic disease and/or they have used rather (even retrospective) restrictive phenotypic inclusion criteria; this has probably contributed to the lack of awareness about disease heterogeneity. In such case we might wonder whether or not, the clinical, phenotypical and genetic diversity of BPDCN (e.g. the maturational stage of blast cells and/or their genetic profile) could contribute to further subclassify this entity, similarly to what happens with other neoplasms, such as B and T-cell malignancies or even AML [16].
Here we describe a relatively large series of 46 BPDCN classified into three subgroups, based on the expression of maturation-associated immunophenotypic markers on tumor vs. normal $\mathrm{pDC}$ and $\mathrm{pDC}$ precursors. Our major goal was to investigate whether the stage of maturational arrest of pDC tumor cells would be associated with distinct and unique clinico-biological and prognostic features of the disease.

\section{RESULTS}

\section{Clinical and laboratory features at presentation}

From all 46 cases analyzed, four $(9 \%)$ were children (median age of 11 years; range: 8 to 12 years) and 42 were adults (median age of 71 years; range: 25 to 91 years), with a clear male predominance: 35 males (76\%) vs. 11 females (24\%) (Table 1). Most cases (27/45, $60 \%$ ) consulted because of organ involvement (e.g. skin lesions) in association with B symptoms (32/45 cases, $71 \%$ ) (Table 1). In a smaller proportion of cases, diagnosis was made because of bleeding $(6 / 45,13 \%)$, bone pain $(4 / 45,9 \%)$ or just the presence of cytopenias with or without blast cells in a routine blood analysis $(5 / 44,11 \%)$. In line with this, most cases presented with extramedullary involvement $(33 / 45,73 \%)$ mainly consisting of skin lesions (29/45 cases, $64 \%)$ and/or, to a lesser extent, testis (6\%) and central nervous system (CNS) involvement (9\% of cases). Presence of lymphadenopathies, splenomegaly and hepatomegaly was detected on physical examination in $51 \%, 38 \%$ and $22 \%$ of cases, respectively. Five patients $(16 \%)$ had an associated myelodysplastic syndrome (MDS) and 3 (7\%) had other non-hematological neoplasms (prostate $-n=2$ - and colon cancer).

Blood cell counts revealed leukocytosis $\left(>10 \times 10^{9}\right.$ $\mathrm{WBC} / \mathrm{l})$ in $33 \%$ of the cases, anemia $(<100 \mathrm{~g}$ hemoglobin/l) in $63 \%$, thrombocytopenia $(<100 \times 10 \% / 1)$ in $64 \%$ of the cases and neutropenia $\left(<1.5 \times 10^{9} / 1\right)$ in around half $(48 \%)$ of cases (Table 2). LDH serum levels were increased in $55 \%$ of the patients. The majority of cases $(61 \%$ and $93 \%)$ showed presence of blast cells in both PB (median blast cell percentage of $39 \%$; range: $2 \%$ to $83 \%$ ) and $\mathrm{BM}$ (median of $78 \%$; range: $4 \%$ to $100 \%$ ), respectively.

\section{Immunophenotypic subgroups of blastic plasmacytoid dendritic cell neoplasms}

Patients with BPDCN were divided into three groups according to the maturational stage of the blast/ tumor cells as defined by the pattern of expression of CD34 and CD117: 1) immature blastic pDC neoplasms 
Table 1: Clinical characteristics of blastic plasmacytoid dendritic cell neoplasms patients classified according to their maturation-associated immunophenotypic profile

\begin{tabular}{|c|c|c|c|c|c|}
\hline \multirow[b]{3}{*}{ Demographics } & \multicolumn{5}{|c|}{ Blast cell phenotype } \\
\hline & \multirow{2}{*}{$\begin{array}{l}\text { Total cases } \\
\qquad n=46 \\
\end{array}$} & \multirow{2}{*}{$\begin{array}{c}\text { Group 1 } \\
\text { (immature) } \\
n=8\end{array}$} & \multirow{2}{*}{$\begin{array}{c}\text { Group 2 } \\
\text { (intermediate) } \\
n=\mathbf{2 4}\end{array}$} & \multirow{2}{*}{$\begin{array}{c}\begin{array}{c}\text { Group } 3 \\
\text { (mature) }\end{array} \\
n=14\end{array}$} & \multirow[t]{2}{*}{$P$-value } \\
\hline & & & & & \\
\hline Age (years)* & $61 \pm 22(8-91)$ & $68 \pm 22(25-91)$ & $56 \pm 23(8-85)$ & $68 \pm 19(11-83)$ & $.05^{\mathrm{c}}$ \\
\hline Children/Adults & $4 / 42(9 \% / 91 \%)$ & $0 / 8(0 \% / 100 \%)$ & $3 / 21(13 \% / 87 \%)$ & $1 / 13(7 \% / 93 \%)$ & NS \\
\hline Sex (male/female) & $35 / 11(76 \% / 24 \%)$ & $6 / 2(75 \% / 25 \%)$ & $15 / 9(63 \% / 37 \%)$ & $14 / 0(100 \% / 0 \%)$ & $.008^{\mathrm{c}}$ \\
\hline \multicolumn{6}{|l|}{ Reason for consulting } \\
\hline Routine blood analysis & $5 / 44(11 \%)$ & $0 / 6(0 \%)$ & $3 / 24(13 \%)$ & $2 / 14(14 \%)$ & NS \\
\hline B \& other general symptoms & $32 / 45(71 \%)$ & $6 / 7(86 \%)$ & $17 / 24(71 \%)$ & $9 / 14(64 \%)$ & NS \\
\hline Bleeding & $6 / 45(13 \%)$ & $1 / 7(14 \%)$ & $3 / 24(13 \%)$ & $2 / 14(14 \%)$ & NS \\
\hline Bone pain & $4 / 45(9 \%)$ & $0 / 7(0 \%)$ & $4 / 24(17 \%)$ & $0 / 14(0 \%)$ & NS \\
\hline Organ involvement & $27 / 45(60 \%)$ & $0 / 7(0 \%)$ & $14 / 24(58 \%)$ & $13 / 14(93 \%)$ & $\leq .03^{\mathrm{a}, \mathrm{b}, \mathrm{c}}$ \\
\hline \multicolumn{6}{|l|}{ Physical examination } \\
\hline Adenopathies & $23 / 45(51 \%)$ & $0 / 7(0 \%)$ & $14 / 24(58 \%)$ & $9 / 14(64 \%)$ & $.007^{\mathrm{a}, \mathrm{b}}$ \\
\hline Splenomegaly & $17 / 45(38 \%)$ & $0 / 7(0 \%)$ & $13 / 24(54 \%)$ & $4 / 14(29 \%)$ & $.01^{\mathrm{a}}$ \\
\hline Hepatomegaly & $10 / 45(22 \%)$ & $0 / 7(0 \%)$ & $7 / 24(29 \%)$ & $3 / 14(21 \%)$ & NS \\
\hline Extramedullary involvement & $33 / 45(73 \%)$ & $1 / 7(14 \%)$ & $19 / 24(79 \%)$ & $13 / 14(93 \%)$ & $\leq .004^{\mathrm{a}, \mathrm{b}}$ \\
\hline - Skin ${ }^{1}$ & $29 / 45(64 \%)$ & $1 / 7(14 \%)$ & $16 / 24(67 \%)$ & $12 / 14(86 \%)$ & $\leq .02^{\mathrm{a}, \mathrm{b}}$ \\
\hline - CNS & $4 / 45(9 \%)$ & $0 / 7(0 \%)$ & $3 / 24(13 \%)$ & $1 / 14(7 \%)$ & NS \\
\hline - Testis ${ }^{2}$ & $2 / 34(6 \%)$ & $0 / 5(0 \%)$ & $1 / 15(7 \%)$ & $1 / 14(7 \%)$ & NS \\
\hline \multicolumn{6}{|l|}{ Clinical history } \\
\hline Associated neoplasia & $3 / 44(7 \%)$ & $0 / 6(0 \%)$ & $1 / 24(4 \%)$ & $2 / 14(14 \%)$ & NS \\
\hline Myelodysplastic syndrome & $5 / 32(16 \%)$ & $2 / 6(33 \%)$ & $1 / 19(5 \%)$ & $2 / 7(29 \%)$ & NS \\
\hline
\end{tabular}

Results expressed as number of cases from all cases with available data and (percentage) or as *mean \pm one standard deviation (range). Statistically significantly differences were found between agroup 1 group 2, broup 1 group 3 and ${ }^{\text {ggroup }} 2$ group $3 .{ }^{1}$ None showed mucosal involvement, ${ }^{2}$ only in male patients, both children. NS: no statistically significant differences $(p>0.05)$, CNS: central nervous system.

(8/46 cases; 17\%) showed expression of CD34 in at least a fraction of the blast cells; 2) intermediate blastic pDC neoplasms (24/46 patients; 52\%) typically displayed partial positivity for CD117 in the absence of CD34 expression on the blast cells, and; 3 ) mature cases (14/46 cases; $30 \%)$ had a CD34- ${ }^{-}$D $117^{-}$tumor pDC immunophenotype. Of note, among all immature cases (Group 1) neoplastic pDC systematically coexisted with another blast cell population of myeloid or mixed myeloid plus B-lymphoid origin, accounting for a median of $50 \%$ of the whole blast cell population (range: $30 \%$ to $90 \%$ ); such coexisting non-pDC lineage blast cells systematically showed strong CD34 and CD117 expression, whereas the pDC component was typically partially positive for CD34 and negative or dim positive for CD117 (Figure 1J, 1K, and 1L). In contrast, both intermediate (Group 2) and mature (Group 3) blastic pDC neoplasms showed no blast/tumor cell population other than the $\mathrm{pDC}$, all these cases being systematically negative for CD34 by definition. Expression of CD117 (in the absence of CD34) was restricted per definition to Group 2, with a median percentage of CD $117^{+}$ cells of $18 \%$ (range: $5 \%$ to $100 \%$ ).

Other immunophenotypic markers which showed different patterns of expression on pDC blast 
Table 2: Blastic plasmacytoid dendritic cell neoplasms classified according to their maturationassociated immunophenotypic profile: laboratory parameters

\begin{tabular}{|c|c|c|c|c|c|c|}
\hline & \multicolumn{5}{|c|}{ Blast cell phenotype } \\
\hline & & Total cases & $\begin{array}{c}\text { Group } 1 \\
\text { (immature) }\end{array}$ & $\begin{array}{c}\text { Group 2 } \\
\text { (intermediate) }\end{array}$ & $\begin{array}{l}\text { Group } 3 \\
\text { (mature) }\end{array}$ & $P$-value \\
\hline \multicolumn{2}{|c|}{ Laboratory parameters } & $n=46$ & $n=8$ & $n=24$ & $n=14$ & \\
\hline \multicolumn{2}{|c|}{ Anemia $(<100 \mathrm{~g} / \mathrm{l})$} & $28 / 44(64 \%)$ & $6 / 7(86 \%)$ & $16 / 24(67 \%)$ & $6 / 13(46 \%)$ & NS \\
\hline \multicolumn{2}{|c|}{ Leukopenia $\left(<4 \times 10^{9} / 1\right)$} & $13 / 43(30 \%)$ & $4 / 7(57 \%)$ & $8 / 23(35 \%)$ & $1 / 13(8 \%)$ & $.03^{\mathrm{a}}$ \\
\hline \multicolumn{2}{|c|}{ Neutropenia $\left(<1.5 \times 10^{9} / 1\right)$} & $20 / 41(49 \%)$ & $6 / 7(86 \%)$ & $12 / 22(55 \%)$ & $2 / 12(17 \%)$ & $\leq .04^{\mathrm{a}, \mathrm{b}}$ \\
\hline \multicolumn{2}{|c|}{ Thrombocytopenia $\left(<100 \times 10^{9} / 1\right)$} & $28 / 43(65 \%)$ & $3 / 7(43 \%)$ & $16 / 24(65 \%)$ & $9 / 12(75 \%)$ & NS \\
\hline \multicolumn{2}{|c|}{ Leukocytosis $\left(>10 \times 10^{9} / 1\right)$} & $14 / 43(33 \%)$ & $0 / 7(0 \%)$ & $6 / 23(26 \%)$ & $8 / 13(62 \%)$ & $\leq .04^{\mathrm{a}, \mathrm{b}}$ \\
\hline \multicolumn{2}{|c|}{ Elevated LDH ( $\geq 450 \mathrm{U} / 1)$} & $22 / 40(55 \%)$ & $1 / 6(17 \%)$ & $11 / 21(52 \%)$ & 10/13 (77\%) & $.02^{\mathrm{a}}$ \\
\hline \multicolumn{7}{|c|}{ Presence of blast cells (by morphology) } \\
\hline \multirow[t]{2}{*}{ Peripheral blood } & $\%$ cases & $27 / 44(61 \%)$ & $4 / 7(57 \%)$ & $14 / 24(58 \%)$ & $9 / 13(69 \%)$ & NS \\
\hline & $\%$ blast cells ${ }^{1 *}$ & $39 \%(2 \%-83 \%)$ & $11 \%(2 \%-35 \%)$ & $45 \%(2 \%-80 \%)$ & $39 \%(10 \%-83 \%)$ & NS \\
\hline \multirow[t]{2}{*}{ Bone marrow } & $\%$ cases & $41 / 44(93 \%)$ & $8 / 8(100 \%)$ & $21 / 24(88 \%)$ & $12 / 12(100 \%)$ & NS \\
\hline & $\%$ blast cells ${ }^{1 *}$ & $78 \%(4 \%-100 \%)$ & $68 \%(46 \%-73 \%)$ & $80 \%(18 \%-99 \%)$ & $85 \%(4 \%-100 \%)$ & NS \\
\hline
\end{tabular}

Results expressed as number of cases from all cases with available data (percentage) or as *median (range).

Statistically significantly differences were found between ${ }^{a}$ group 1 group 3 and ${ }^{b}$ group 2 group $3 .{ }^{1}$ Only in cases with blast cells. NS: no statistically significant differences $(p>0.05)$ found, LDH: lactate dehydrogenase; $\beta_{2}$-microg: $\beta_{2}$-microglobulin. No statistical differences were observed among the groups regarding creatinine and C-reactive protein levels.

cells included (Supplementary Table 2 and Figure 2): CD7 and CD33 which showed a greater expression among cases in the intermediate immunophenotypic Group $2(p=.008$ and $p=.04$, respectively) and to a lesser extent also, in case of CD7, in Group $3(p>.05)$; CD56, which was dimly expressed only in a fraction of cases in Group 1, but widely and intensely positive on tumor cells from Group 2 and Group 3 cases $(p \leq .04)$, and; NG2, a marker that was absent in Group 1 cases $(p \leq .03)$ but clearly expressed in most of the other more mature Group 2 and Group 3 patients (Figure 1, panel II, plots $\mathrm{M}$ to $\mathrm{X}$ and Figure 2).

\section{Clinical and laboratory features of the distinct maturation-associated subgroups of BPDCN}

Overall, no significant differences were observed among the three phenotypic groups of BPDCN, as regards the distribution of patients according to age. Although a clear male predominance was found in all groups, this was significantly more pronounced in Group 3, where all 14 cases were males $(p<.008)$ (Table 1). Patients in the three groups showed a similar reason for consulting except for cases in Group 1 which less frequently referred because of organ involvement. In line with this, Group 1 cases also showed a significantly lower frequency (vs. the other two groups) of extramedullary involvement (14\% vs.
$79 \%$ and $93 \%, p \leq .004$ ), lymphadenopathies ( $0 \%$ vs. $58 \%$ and $64 \%, p \leq .007)$ and splenomegaly ( $0 \%$ vs. $54 \%$ and $29 \%, p=.01)$. Group 2 cases showed intermediate profiles between those of Group 1 and Group 3 patients, as regards the frequency of extramedullary involvement, particularly of skin lesions.

Despite similar levels of BM and PB infiltration by tumor pDCs were found among the three groups, the frequency of anemia, leukopenia and neutropenia progressively decreased from Group 1 to Group 2 and Group 3 cases (Table 2). In contrast, the frequency of thrombocytopenia was slightly higher among the latter two groups. The frequency of cases with increased LDH levels was significantly higher in Group 3 vs. Group 1 cases.

\section{Patient treatment and outcome}

All 4 Group 1 patients who were treated with curative intention, systematically received an AML-type regimen; this is in contrast with Group 3 cases, who more frequently received either lymphoma (6/9 cases) or acute lymphoblastic leukemia (ALL; 3/9 patients) directed therapies $(p=.01)$ (Table 3$)$. In turn, Group 2 patients received AML (8/19), ALL (5/19) and lymphoma $(6 / 19)$ associated therapy. Despite the diverse therapies administered, complete remission (CR) was achieved in the great majority of cases (92\%) who completed 
Panel I
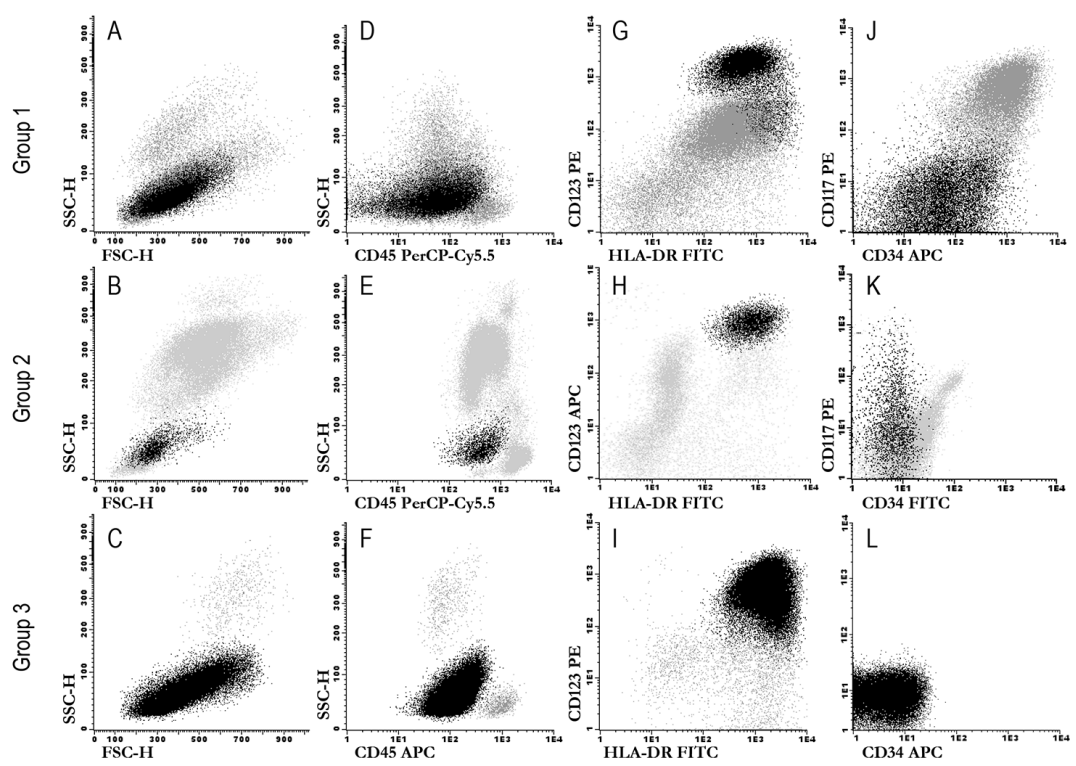

Panel II
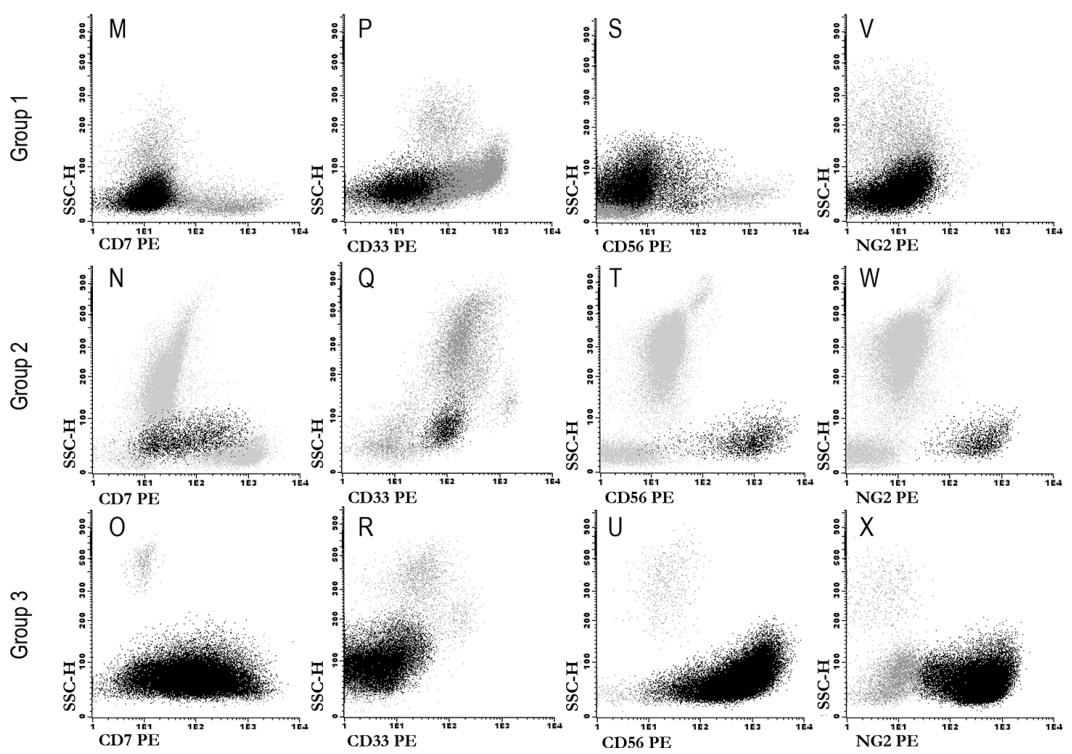

Figure 1: Illustrating dot plots of the three immunophenotypically defined groups of BPDCN. The neoplastic plasmacytoid dendritic cell population is depicted as black dots, whereas other leukocytes are depicted in gray. Panel I: plots A to I illustrate a combination of markers which are useful for the identification of blastic pDC, while plots J to L show the pattern of expression of CD34 and CD117 for representative cases from the different maturation-associated groups of BPDC neoplasms here defined. Panel II: plots M to X display the pattern of expression observed for those markers found to be expressed at statistically different levels among the three maturationassociated groups of BPDC neoplasms.

the treatment protocol $(n=25)$, regardless of their phenotypic group $(p>.05)$; nevertheless, the outcome was poor with a median overall survival (OS) of only 11 months due to early relapse. Interestingly, relapse and/ or progression at the CNS level was observed in a high proportion of cases $(33 \%)$, mostly among Group 2 and Group 3 (29\% and 50\%, respectively) patients (Table 3); this was even more frequent when only patients who achieved CR were evaluated (60\%), particularly in those cases where a lymphoma-type therapy was administered (Supplementary Table 3). Overall, no significant differences were observed in the outcome of the patients from the three distinct immunophenotypic groups (Table 3 and Figure $3 \mathrm{~A}$ and $3 \mathrm{~B}$ ). In contrast, adulthood (age at diagnosis $>15$ years; $p=.04$ ) (Figure 3C), presence of lymphadenopathies $(p=.03)$ and hepatomegaly $(p=.03)$ 


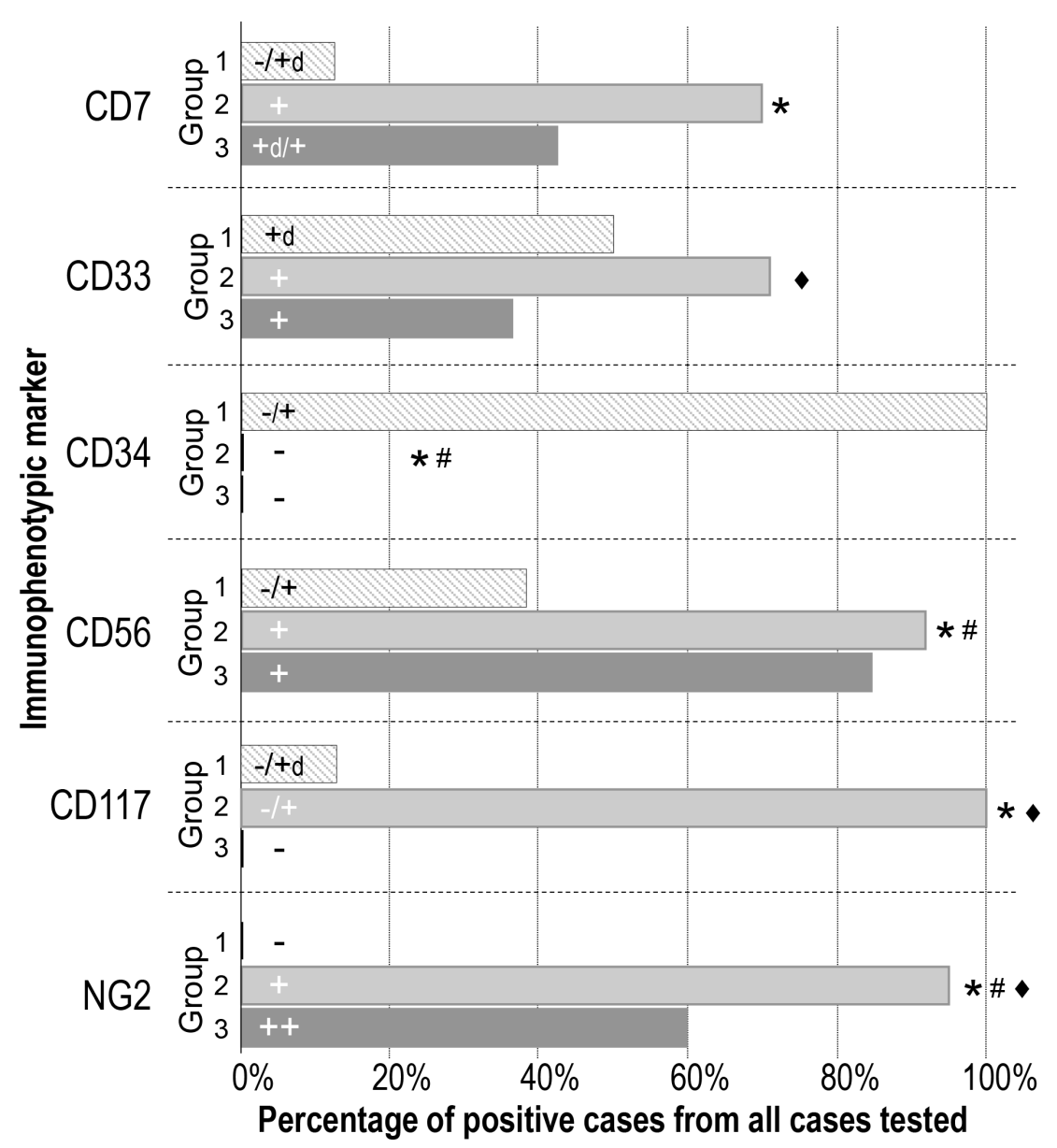

Figure 2: Immunophenotypic differences observed for individual markers on neoplastic pDC from PBDCN patients classified into the three different maturation-associated groups defined in this study. Only those markers that showed statistically significant differences -CD7, CD33, CD34, CD56, CD117 and NG2- among the three maturation-associated groups of BPDC neoplasms are shown; the percentage of positive cases and the pattern of expression (intensity) observed for the above listed markers are represented as bars for each group of patients. The correspondence between MFI values and the different categories of intensity of expression defined for the individual markers is shown in Supplementary Table 2. Statistically significant differences were found between *Group 1 vs. Group 2, \#Group 1 vs. Group 3 and $\bullet$ Group 2 vs. Group 3.

(Figure 3D and 3E), skin lesions ( $p=.04$ ) (Figure 3F), increased serum LDH $(\geq 450 \mathrm{U} / \mathrm{l} ; p=.001)$ (Figure $3 \mathrm{H})$ and $\beta_{2}$-microglobulin ( $\left.\geq 3 \mathrm{mg} / \mathrm{l} ; p=.02\right)$ were all associated with a poorer outcome (Table 4). In turn, leukopenia $(p=.05)$ (Figure 3G), administration of ALL-type therapy (Figure 3I) and allogeneic stem cell transplantation (Figure 3J) ( $p=.03$ and $p=.04$, respectively) were associated with a better outcome. Multivariate analysis of prognostic factors (Table 4) showed that serum LDH levels were the only independent prognostic factor for OS in aggressively-treated patients $(p=.005, \mathrm{HR}=6.6 ; 95 \%$ $\mathrm{CI}=1.8-24.8$ ).

\section{DISCUSSION}

$\mathrm{BPDCN}$ is a rare but very aggressive disease whose nomenclature, ontogeny and underlying biology have evolved over the years, since its first description by Brody et al. in 1995 [17]. Despite the number of cases reported in recent years has increased, as well as our knowledge about the biology of its postulated normal cellular counterpart (i.e. pDC lineage cells) $[9,18-20]$, the diagnosis of the disease still remains a challenge. This is due in part, to the clinical and phenotypical diversity observed among the patients and the overlapping features with other hematologic malignancies. In order to elucidate whether the clinical heterogeneity of BPDCN is related to the maturation stage of pDC tumor cells, here we analyzed a relatively large series of 46 patients, whose general clinical features were fully compatible with those previously reported for this rare entity $[6,7]$, except for the proportion of cases presenting with skin involvement that was lower $(64 \%$ vs. $76 \%-100 \%)$ in our vs. other series $[6,7,15,21]$. Although there is no definitive explanation for such difference, it might be due to the fact that until recently, skin lesions have been considered one of the major features 
Table 3: Type of therapy and clinical outcome of patients with BPDCN classified according to the immunophenotypic-associated maturation profile of blast cells

\begin{tabular}{|c|c|c|c|c|c|}
\hline \multirow[b]{2}{*}{ Type of therapy administered } & \multicolumn{5}{|c|}{ Blast cell phenotype } \\
\hline & $\begin{array}{l}\text { Total cases } \\
\qquad n=46\end{array}$ & $\begin{array}{c}\text { Group 1 } \\
\text { (immature) } \\
n=8\end{array}$ & $\begin{array}{c}\text { Group 2 } \\
\text { (intermediate) } \\
n=\mathbf{2 4}\end{array}$ & $\begin{array}{c}\text { Group } 3 \\
\text { (mature) } \\
n=14\end{array}$ & $P$-value \\
\hline AML-type & $12 / 45(27 \%)$ & $4 / 8(50 \%)$ & $8 / 23(35 \%)$ & $0 / 14(0 \%)$ & $\leq .01^{\mathrm{a}, \mathrm{b}}$ \\
\hline High risk ALL-type & $8 / 45(18 \%)$ & $0 / 8(0 \%)$ & $5 / 23(22 \%)$ & $3 / 14(21 \%)$ & NS \\
\hline $\mathrm{C}(\mathrm{H}) \mathrm{OP}$ and $\mathrm{C}(\mathrm{H}) \mathrm{OP}$-like type & $12 / 45(27 \%)$ & $0 / 8(0 \%)$ & $6 / 23(26 \%)$ & $6 / 14(43 \%)$ & $.04^{\mathrm{a}}$ \\
\hline AHSC transplantation & $5 / 45(11 \%)$ & $1 / 8(13 \%)$ & $4 / 23(17 \%)$ & $0 / 14(0 \%)$ & NS \\
\hline Palliative & $10 / 45(22 \%)$ & $3 / 8(38 \%)$ & $3 / 23(13 \%)$ & $4 / 14(29 \%)$ & NS \\
\hline No treatment & $3 / 45(7 \%)$ & $1 / 8(13 \%)$ & $1 / 23(4 \%)$ & $1 / 14(7 \%)$ & NS \\
\hline \multicolumn{6}{|l|}{ Clinical outcome } \\
\hline Median OS (months) & $7(4-10)$ & $2(0-4)$ & $10(5-15)$ & $4(0-10)$ & NS \\
\hline Complete remission $^{1}$ & $23 / 25(92 \%)$ & $2 / 2(100 \%)$ & $14 / 15(93 \%)$ & $7 / 8(88 \%)$ & NS \\
\hline Relapse & $17 / 23(74 \%)$ & $1 / 2(50 \%)$ & $10 / 14(71 \%)$ & $6 / 7(86 \%)$ & NS \\
\hline CNS relapse/progression & $10 / 30(33 \%)$ & $0 / 3(0 \%)$ & $5 / 17(29 \%)$ & $5 / 10(50 \%)$ & NS \\
\hline $\begin{array}{l}\text { Median OS of aggressively treated } \\
\text { non-transplanted cases (months) }\end{array}$ & $11(5-17)$ & $23^{2}$ & $11(7-15)$ & $10(0-23)$ & NS \\
\hline Overall mortality & $42 / 46(91 \%)$ & $7 / 8(88 \%)$ & $22 / 24(92 \%)$ & $13 / 14(93 \%)$ & NS \\
\hline Early deaths & $12 / 46(26 \%)$ & $4 / 8(50 \%)$ & $4 / 24(17 \%)$ & 4/14 (29\%) & NS \\
\hline Deaths after remission & $18 / 23(78 \%)$ & $1 / 2(50 \%)$ & $11 / 14(79 \%)$ & $6 / 7(86 \%)$ & NS \\
\hline
\end{tabular}

Results expressed as number of cases from all cases with available data (percentage). Statistically significantly differences were found between a group 1 group 3 and ${ }^{b}$ group 2 versus group 3. ${ }^{1}$ Only in aggressively treated patients, ${ }^{2}$ only one case. BPDC: blastic plasmacytoid dendritic cell; AML: acute myeloblastic leukemia; ALL: acute lymphoblastic leukemia; NS: no statistically significant differences ( $p>0.05$ ); AHSC: allogeneic hematopoietic stem cell; OS: overall survival; CNS: central nervous system.

that point to the diagnosis of BPDCN and consequently, a fraction of BPDCN patients, who have no cutaneous manifestations, might have gone undetected/not identified. Alternatively, a bias in sample selection could also exist, as more blood and BM vs. tissue samples from complex cases are referred from other centers to our institution.

Once we grouped our cases according to the immunophenotypic maturation profile of pDC-lineage tumor cells, important differences were noted between the immature and the more mature cases, the intermediate group showing also intermediate features. Despite CD34 has been frequently considered as an exclusion marker for the diagnosis of BPDCN [11, 22], this marker was expressed in a fraction of pDC-lineage commited blast cells in around one fifth of our cases. Interestingly, these CD $34^{+}$BPDCN cases systematically had a second CD $34^{+}$ blast cell population with a minimally differentiated (nonlymphoid) phenotype. These results support and extend on previous observations by the Hellenic Dendritic Cell
Leukemia Study Group, which found similar phenotypic and clinical characteristics to those of our Group 1 cases in $4 / 26(15 \%)$ of their BPDCN patients [6]. If the WHO 2008 criteria [2] would be strictly applied, these cases would be classified as acute leukemia of ambiguous or minimally differentiated myeloid lineage, because of the lack of clear differentiation markers for cell lineages other than pDC. Of note, lymphoid lineage-committed blast cells have also been reported in a smaller proportion of these $\mathrm{CD} 34^{+}$cases ([6] and personal unpublished observations). Previous studies have shown that among $\mathrm{CD}^{+} 4^{+} \mathrm{pDC}$ cases, both the pDC lineage-committed and the minimally differentiated blast cell population coexisting in individual patients, share the same chromosomal aberrations [23, 24], which suggests that both cell populations arise from a common ancestral leukemia cell, and that the pDC-lineage component may represent the more differentiated blast cell compartment. Of note, in these $\mathrm{CD} 34^{+}$cases, the pDC-lineage committed 

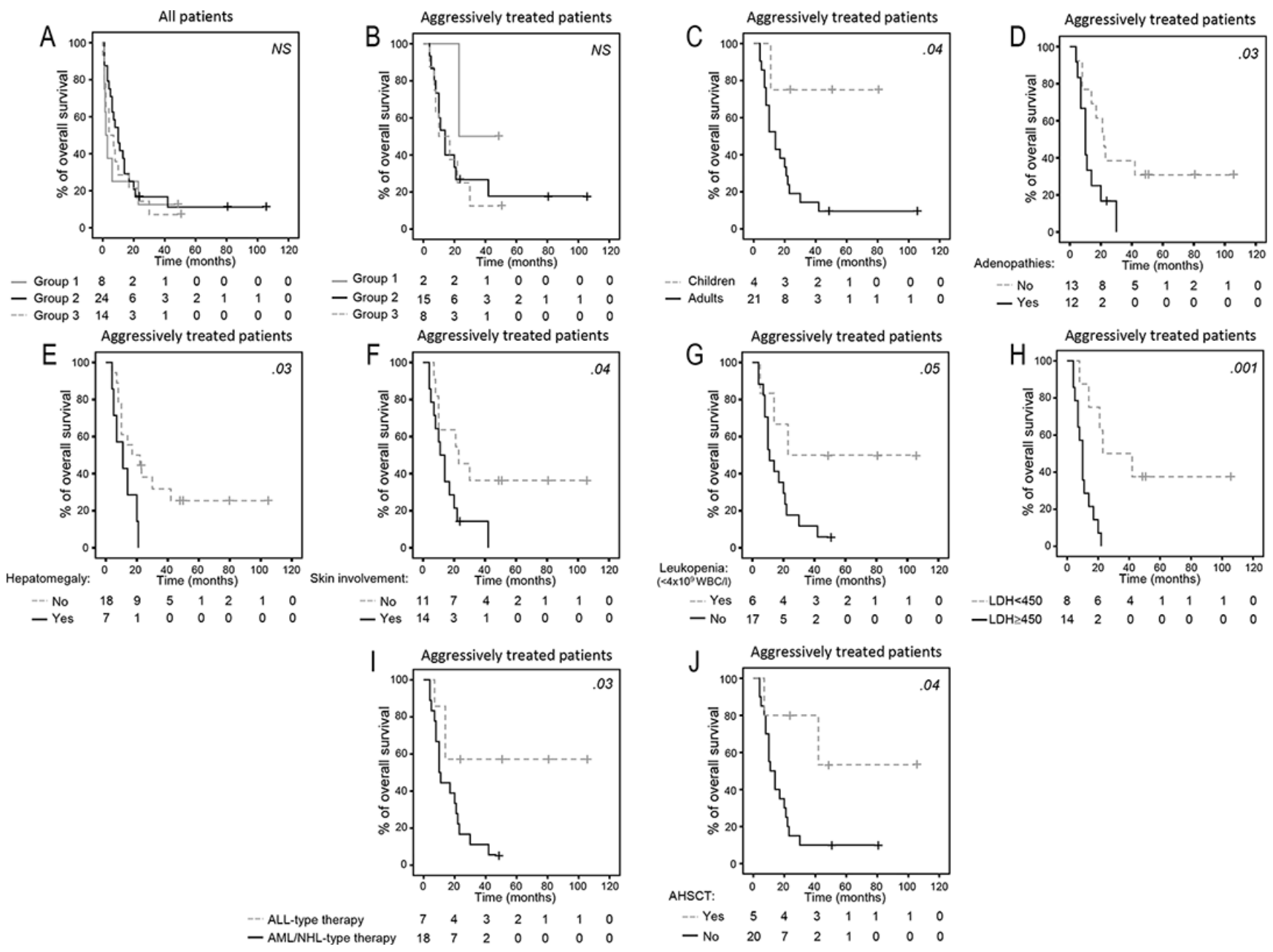

Figure 3: Overall survival of patients with BPDCN. Stratified according to the three pDC maturation-associated groups of patients. Panels A and B, age at diagnosis panel C, presence of lymphadenopathies panel D, hepatomegaly panel E, skin lesions panel F, leukopenia panel G, lactate dehydrogenase $(\mathrm{LDH})$ serum levels panel $\mathbf{H}$, type of systemic therapy administered -acute lymphoid leukemia (ALL)-type vs. acute myeloid leukemia (AML) or lymphoma (NHL)-type therapies- panel I, including allogeneic hematopoietic stem cell transplantation (AHSCT) panel J. For all panels but panel A, only those patients who had been treated with an intention to cure, are represented.

blast cell population frequently did not show aberrant expression of either CD56 or NG2 [6,23], in contrast to most other more mature (Group 2 and Group 3) BPDCN cases. Furthermore, this subset of CD34+ BPDCN cases also showed a unique clinical behavior vs. the other cases; e.g. at presentation they typically lacked skin lesions and extramedullary disease. These results indicate that in these patients blast cells appear to be almost exclusively confined to the BM with some spreading to $\mathrm{PB}$, reflecting a typical "acute leukemia-like" behavior, associated in most cases with multiple cytopenias. This is in line with the immunophenotypic profile of blast cells from cases classified as immature (Group 1) BPDCN, supporting the notion that they would mimic a stem cell malignancy whose blast cells would have limited ability to differentiate into the early stages of pDC lineage. Conversely, patients classified under Group 3, displayed a more mature pDC immunophenotype, associated with a greater frequency of extramedullar involvement (particularly in the skin) and spread into the lymph nodes and other secondary lymphoid tissues; such clinical behavior mimics that of aggressive lymphomas. Altogether, these results point out to a more mature and differentiated tumor $\mathrm{pDC}$, blocked at a stage where the $\mathrm{pDC}$ precursor already leaves the $\mathrm{BM}$ via $\mathrm{PB}$, with a greater migration capacity into peripheral tissues and secondary lymphoid tissues, which translates into frequent extramedullary organ involvement. In line with this hypothesis, Group 2 cases showed an intermediate phenotypic and clinical behavior between the other two groups (immature and mature) of BPDCN patients. These results support the notion that BPDCN originates from a $\mathrm{BM}$ cell precursor that secondarily involves the skin [25] and other peripheral tissues and lymphoid organs, at least in the great majority of cases. 
Table 4: Prognostic factors (univariate and multivariate analysis) for overall survival among aggressively-treated patients with blastic plasmacytoid dendritic cell neoplasms $(n=25)$

\begin{tabular}{|c|c|c|c|c|c|c|c|}
\hline Patient features & & $\begin{array}{l}\% \text { of } \\
\text { cases }\end{array}$ & $\begin{array}{c}\text { Median } \\
\text { (months) }\end{array}$ & Uni $P$-value & $\begin{array}{c}\text { Multi } \\
P \text {-value }\end{array}$ & $\begin{array}{c}\text { Hazard } \\
\text { Ratio }\end{array}$ & $95 \%$ CI \\
\hline \multirow{2}{*}{ Age } & $\leq 15 \mathrm{y}$ & 16 & NR & \multirow{2}{*}{.04} & & & \\
\hline & $>15 \mathrm{y}$ & 84 & 14 & & & & \\
\hline \multirow{2}{*}{ Adenopathies } & No & 52 & 22 & \multirow{2}{*}{.03} & & & \\
\hline & Yes & 48 & 10 & & & & \\
\hline \multirow{2}{*}{ Hepatomegaly } & No & 72 & 17 & \multirow{2}{*}{.03} & & & \\
\hline & Yes & 28 & 11 & & & & \\
\hline \multirow{2}{*}{ Skin involvement } & No & 44 & 23 & \multirow{2}{*}{.04} & & & \\
\hline & Yes & 56 & 11 & & & & \\
\hline \multirow{2}{*}{ Leukopenia $\left(<4 \times 10^{9} / 1\right)$} & No & 74 & 11 & \multirow{2}{*}{.05} & & & \\
\hline & Yes & 26 & 23 & & & & \\
\hline \multirow{2}{*}{ Elevated LDH $(\geq 450 \mathrm{U} / 1)$} & No & 36 & 23 & \multirow{2}{*}{.001} & \multirow{2}{*}{.005} & \multirow{2}{*}{6.6} & \multirow{2}{*}{$1.8-24.8$} \\
\hline & Yes & 64 & 10 & & & & \\
\hline \multirow{2}{*}{ Increased $\beta_{2}-\mathrm{M}(\geq 3 \mathrm{mg} / \mathrm{l})$} & No & 43 & 42 & \multirow{2}{*}{.02} & & & \\
\hline & Yes & 57 & 10 & & & & \\
\hline \multirow{2}{*}{ ALL-type treatment } & No & 28 & 10 & \multirow{2}{*}{.03} & & & \\
\hline & Yes & 72 & NR & & & & \\
\hline \multirow{2}{*}{ AHSC transplantation } & No & 80 & 11 & \multirow{2}{*}{.04} & & & \\
\hline & Yes & 20 & NR & & & & \\
\hline \multirow{2}{*}{ Relapse } & No & 32 & NR & \multirow{2}{*}{.02} & & & \\
\hline & Yes & 68 & 14 & & & & \\
\hline
\end{tabular}

Uni: univariate analysis, Multi: multivariate analysis, CI: confidence interval, NR: not reached, LDH: lactate

dehydrogenase, $\beta_{2}$-M: $\beta_{2}$-microglobulin, ALL: acute lymphoblastic leukemia, AHSC: allogeneic hematopoietic stem cell.

Despite the here defined maturation-associated subgroups of BPDCN displayed a clearly different clinical behavior at presentation, no significant differences were observed among them as regards disease outcome, with systematically low (i.e. less than a year) OS rates. However, it should be noted that different treatments were given to these patients due to their heterogeneous clinical presentation and equivocal tumor cell features at presentation. Of note, high CR rates were obtained, regardless of the type of therapy administered. However, most cases showed an aggressive clinical course with early recurrence of the disease, resistance to therapy and a dismal prognosis with median overall survival rates of less than a year, fully in line with previous observations [25]. Despite the above, more detailed analysis of patient outcome according to therapy showed that cases treated with ALL-type protocols had a better outcome than the other patients, particularly than those who received lymphoma-type regimens (Supplementary Table 3); these results are also in line with previous observations $[6,21]$, although younger patients (e.g. children) were mostly included in the group treated with ALL-like protocols. Therefore, the question remains about whether the treatment itself or age at diagnosis, would explain the apparently better prognosis of this subgroup of BPDCN patients. In this regard, it should also be emphasized that the only two adults who survived so far, were both treated with an allogeneic stem cell transplant following ALLtype therapy in one case and AML-type chemotherapy in the other patient. Despite the low number of cases included in each group, our results would reinforce previous observations suggesting a better outcome for patients treated with ALL-type and/or allogeneic stem cell transplantation $[6,7,21,26]$.

Although the potential impact of age cannot be ruled out, we may speculate that the better outcome of cases treated with ALL-type chemotherapy could be due to systematic administration of CNS prophylaxis, 
since a high percentage of the cases $(60 \%)$ showed CNS involvement at relapse, particularly among nonALL-type chemotherapy treated patients (all but one, who received an ALL-type protocol). Despite the broad variety of prognostic factors -including therapy- found to be associated with patient outcome, LDH emerged as the only independent prognostic factor for aggressivelytreated patients, in line with the strong predictive value of LDH in other hematological malignancies, particularly mature/peripheral lymphoid tumors $[27,28]$.

In summary, here we show that tumor cells from BPDCN may show a highly variable maturational profile, which translates into a heterogeneous clinical behavior ranging from that of acute leukemia to peripheral/mature lymphomas, such wide clinical spectrum potentially leading also to variable differential diagnoses and administration of distinct treatment modalities. Despite the dismal prognosis of the great majority of patients, usage of ALL-type therapy with CNS prophylaxis and/ or allogeneic stem cell transplantation appears to be, among all regimens administered, the only effective ones. Overall, these results support the unique clinical and prognostic behavior of this subgroup of non-lymphoid neoplasms, which requires redefined diagnostic criteria and improved/novel [29] treatment strategies/regimens (e.g. CNS prophylaxis and consolidation regimens) for prolonged $\mathrm{CR}$ and survival rates.

\section{MATERIALS AND METHODS}

\section{Patients and samples}

A total of 46 patients ( 4 children and 42 adults; 35 males and 11 females) diagnosed with BPDCN (according to WHO 2008 criteria [2]) and who were referred to the Cytometry Service of the Cancer Research Centre of the University of Salamanca (Salamanca, Spain), were included in this study. Diagnosis was prospectively made, based on co-expression of HLA-DR ${ }^{++}$ and $\mathrm{CD} 123^{+/++}$(which strongly supports a plasmacytoid dendritic cell origin $[11,30]$ ) together with CD4 positivity, dim expression of CD45 and intermediate forward scatter (FSC)/sideward scatter (SSC) values, after blast cell commitment to other myeloid and lymphoid cell lineages had been excluded by morphological, immunophenotypical and molecular analyses (e.g. germline TCR and IGH gene configurations). The vast majority of cases also showed expression of CD36, further supporting a BPDCN diagnosis in the presence of the above referred phenotype.

In every patient, bone marrow (BM), peripheral blood (PB) and/or fine-needle aspiration (FNA) tissue samples were obtained and studied at diagnosis, before any therapy had been administered. Clinical and laboratory data was retrospectively collected from the referring centers. At the moment of closing the study, median follow-up was of 7 months (range: $<1$ to 104 months),
41 patients had died and 5 remained alive. The study was approved by the Ethics Committee of the Cancer Research Center, and performed following the Declaration of Helsinki. Each participant gave his informed consent prior entering the study.

Systemic therapy was administered to 32/46 patients and consisted of standard AML-type (cytarabine in combination with idarubicin, mitoxantrone or daunorubicin), acute lymphoid leukemia (ALL)-type (Spanish PETHEMA LAL-AR/2003 protocol and hyper-CVAD) [31] or lymphoma-type (i.e. $\mathrm{C}(\mathrm{H}) \mathrm{OP}$ ) protocols, according to local criteria at the referring centers. The remaining patients received only palliative care based on local criteria.

\section{Flow cytometry immunophenotyping}

Multiparameter flow cytometry immunophenotypic studies were performed on whole BM, PB and FNA samples obtained from lymphoid tissues and/or skin lesions, using multicolor $[3,4,6-8,11]$ combinations of a large panel of monoclonal antibodies (Supplementary Table 1); since 2009 these included the EuroFlow panels [32]. In all cases, samples were stained using a direct immunofluorescence technique, as described elsewhere [20]. For data acquisition, a FACSCalibur and FACSCanto II flow cytometers (Becton Dickinson Biosciences -BD-, San Jose, CA, USA) were used. The Infinicyt (Cytognos, Salamanca, Spain) software program was used for data analysis.

\section{Cytomorphological and histopathological analyses}

Cytological analysis of May-Grünwald-Giemsa stained $\mathrm{PB}$ and $\mathrm{BM}$ smears was performed by conventional microscopy. In turn, conventional histopathological analyses were also performed in parallel for those cases showing lymph node and/or skin involvement, to further confirm tissue infiltration by pDC blast cells.

\section{Statistical methods}

Conventional descriptive and comparative statistics Mann-Whitney U non-parametric test (for continuous variables) and the $\chi^{2}$ test (for categorical variables)- were calculated using the PASW 19 program (IBM SPSS Statistics, IBM, Armonk, NY, USA). Overall survival curves (OS) were plotted according to the KaplanMeier method and compared using the (one-sided) log-rank test. Multivariate Cox proportional hazard models (stepwise regression) were applied to explore the independent effect of each parameter under study (including immunophenotypical BPDCN subgrouping) on OS. Hazard ratio and 95\% confidence interval were also estimated. $P$ values $<0.05$ were considered to be associated with statistical significance. 


\section{ACKNOWLEDGMENTS}

The authors would like to thank Carlos Fernández (University of Salamanca), Artur Paiva (Portuguese Institute of Blood and Transplant, Coimbra, Portugal), Carlota Calvo and Ana Godoy (Hospital Miguel Servet, Zaragoza, Spain), Belén Navarro (Hospital Puerta de Hierro, Madrid, Spain), José Antonio Queizán (Hospital General de Segovia, Segovia, Spain), Josefina Grande (Hospital Comarcal del Bierzo, Ponferrada, Spain), Fernando Puente (Hospital San Jorge, Huesca, Spain), Fernando Ramos (Hospital Virgen Blanca, León, Spain), Abelardo Bárez (Hospital Nuestra Señora de Sonsoles, Ávila, Spain), Isana Benet and Amparo Miguel (Hospital General Universitario, Valencia, Spain), Rosario Butrón (Hospital Punta Europa, Algeciras, Spain), Helena Bañas (Hospital Príncipe de Asturias, Alcalá de Henares, Spain), Fernando Principe (Hospital São João, Porto, Portugal), Ángel Ramírez (Hospital Central de Asturias, Oviedo, Spain), Luis Perdiguer (Hospital de Alcañiz, Teruel, Spain), José Tomás Navarro (Hospital Germans Trias i Pujol, Badalona, Spain), Guillermo Martín (Hospital Virgen del Puerto, Plasencia, Spain), Dolores Subirá (Hospital Universitario de Guadalajara, Spain) for their collaboration in this study.

\section{CONFLICTS OF INTEREST}

The authors declare that there are no conflicts of interest to disclose.

\section{GRANT SUPPORT}

This work was supported by grants RD06/0020/0035 and RD12/0036/0048 from RETICS (Instituto de Salud Carlos III, Ministerio de Economía y Competitividad, Madrid, Spain and Fondos FEDER) and grant EDU/878/2004 from Junta de Castilla y León and Fondo Social Europeo.

\section{REFERENCES}

1. Bueno C, Almeida J, Lucio P, Marco J, Garcia R, de Pablos JM, Parreira A, Ramos F, Ruiz-Cabello F, Suarez-Vilela D, San Miguel JF, Orfao A. Incidence and characteristics of CD4(+)/HLA DRhi dendritic cell malignancies. Haematologica. 2004; 89:58-69.

2. Facchetti F, Jones M, Petrella T. 2008; Blastic plasmacytoid dendritic cell neoplasm. In: WHO classification of tumors of hematopoietic and lymphoid tissues. 4th edn. International Agency for Research on Cancer (IARC) Lyon, France: 2008 ; :145-7.

3. Chaperot L, Bendriss N, Manches O, Gressin R, Maynadie M, Trimoreau F, Orfeuvre H, Corront B, Feuillard J, Sotto JJ, Bensa JC, Briere F, Plumas J,
Jacob MC. Identification of a leukemic counterpart of the plasmacytoid dendritic cells. Blood. 2001; 97:3210-3217.

4. Lucioni M, Novara F, Fiandrino G, Riboni R, Fanoni D, Arra M, Venegoni L, Nicola M, Dallera E, Arcaini L, Onida F, Vezzoli P, Travaglino E, Boveri E, Zuffardi O, Paulli M, et al. Twenty-one cases of blastic plasmacytoid dendritic cell neoplasm: focus on biallelic locus 9p21.3 deletion. Blood. 2011; 118:4591-4594.

5. Menezes J, Acquadro F, Wiseman M, Gomez-Lopez G, Salgado RN, Talavera-Casanas JG, Buno I, Cervera JV, Montes-Moreno S, Hernandez-Rivas JM, Ayala R, Calasanz MJ, Larrayoz MJ, Brichs LF, Gonzalez-Vicent M, Pisano DG, et al. Exome sequencing reveals novel and recurrent mutations with clinical impact in blastic plasmacytoid dendritic cell neoplasm. Leukemia. 2014; 28:823-829.

6. Tsagarakis NJ, Kentrou NA, Papadimitriou KA, Pagoni M, Kokkini G, Papadaki H, Pappa V, Marinakis T, Anagnostopoulos NI, Vadikolia C, Anagnostopoulos A, Angelopoulou MK, Terpos E, Poziopoulos C, Anargyrou K, Rontogianni D, et al. Acute lymphoplasmacytoid dendritic cell (DC2) leukemia: results from the Hellenic Dendritic Cell Leukemia Study Group. Leuk Res. 2010; 34:438-446.

7. Pagano L, Valentini CG, Pulsoni A, Fisogni S, Carluccio P, Mannelli F, Lunghi M, Pica G, Onida F, Cattaneo C, Piccaluga PP, Di Bona E, Todisco E, Musto P, Spadea A, D'Arco A, et al. Blastic plasmacytoid dendritic cell neoplasm with leukemic presentation: an Italian multicenter study. Haematologica. 2013; 98:239-246.

8. Herling M, Jones D. CD4+/CD56+ hematodermic tumor: the features of an evolving entity and its relationship to dendritic cells. Am J Clin Pathol. 2007; 127:687-700.

9. Marafioti T, Paterson JC, Ballabio E, Reichard KK, Tedoldi S, Hollowood K, Dictor M, Hansmann ML, Pileri SA, Dyer MJ, Sozzani S, Dikic I, Shaw AS, Petrella T, Stein H, Isaacson PG, et al. Novel markers of normal and neoplastic human plasmacytoid dendritic cells. Blood. 2008; 111:3778-3792.

10. Garnache-Ottou F, Chaperot L, Biichle S, Ferrand C, Remy-Martin JP, Deconinck E, de Tailly PD, Bulabois B, Poulet J, Kuhlein E, Jacob MC, Salaun V, Arock M, Drenou B, Schillinger F, Seilles E, et al. Expression of the myeloid-associated marker CD33 is not an exclusive factor for leukemic plasmacytoid dendritic cells. Blood. 2005; 105:1256-1264.

11. Garnache-Ottou F, Feuillard J, Ferrand C, Biichle S, Trimoreau F, Seilles E, Salaun V, Garand R, Lepelley P, Maynadie M, Kuhlein E, Deconinck E, Daliphard S, Chaperot L, Beseggio L, Foisseaud V, et al. Extended diagnostic criteria for plasmacytoid dendritic cell leukaemia. British journal of haematology. 2009; 145:624-636.

12. Kawai K. CD56-negative blastic natural killer-cell lymphoma (agranular CD4(+)/CD56(+) haematodermic neoplasm)?. The British journal of dermatology. 2005; 152:369-370. 
13. Montes-Moreno S, Ramos-Medina R, Martinez-Lopez A, Barrionuevo Cornejo C, Parra Cubillos A, QuintanaTruyenque S, Rodriguez Pinilla SM, Pajares R, SanchezVerde L, Martinez-Torrecuadrada J, Roncador G, Piris MA. SPIB, a novel immunohistochemical marker for human blastic plasmacytoid dendritic cell neoplasms: characterization of its expression in major hematolymphoid neoplasms. Blood. 2013; 121:643-647.

14. Stenzinger A, Endris V, Pfarr N, Andrulis M, Johrens K, Klauschen F, Siebolts U, Wolf T, Koch PS, Schulz M, Hartschuh W, Goerdt S, Lennerz JK, Wickenhauser C, Klapper W, Anagnostopoulos I, et al. Targeted ultra-deep sequencing reveals recurrent and mutually exclusive mutations of cancer genes in blastic plasmacytoid dendritic cell neoplasm. Oncotarget. 2014; 5:6404-6413.

15. Julia F, Petrella T, Beylot-Barry M, Bagot M, Lipsker D, Machet L, Joly P, Dereure O, Wetterwald M, d'Incan M, Grange F, Cornillon J, Tertian G, Maubec E, Saiag P, Barete $\mathrm{S}$, et al. Blastic plasmacytoid dendritic cell neoplasm: clinical features in 90 patients. The British journal of dermatology. 2013; 169:579-586.

16. Shaffer AL, Rosenwald A, Staudt LM. Lymphoid malignancies: the dark side of B-cell differentiation. Nature reviews. 2002; 2:920-932.

17. Brody JP, Allen S, Schulman P, Sun T, Chan WC, Friedman HD, Teichberg S, Koduru P, Cone RW, Loughran TP Jr. Acute agranular CD4-positive natural killer cell leukemia. Comprehensive clinicopathologic studies including virologic and in vitro culture with inducing agents. Cancer. 1995; 75:2474-2483.

18. Lucio P, Parreira A, Orfao A. CD123 hi dendritic cell lymphoma: an unusual case of non-Hodgkin lymphoma. Ann Intern Med. 1999; 131:549-550.

19. Martin-Martin L, Almeida J, Hernandez-Campo PM, Sanchez ML, Lecrevisse Q, Orfao A. Immunophenotypical, morphologic, and functional characterization of maturation-associated plasmacytoid dendritic cell subsets in normal adult human bone marrow. Transfusion. 2009; 49:1692-1708.

20. Almeida J, Bueno C, Alguero MC, Sanchez ML, Canizo MC, Fernandez ME, Vaquero JM, Laso FJ, Escribano L, San Miguel JF, Orfao A. Extensive characterization of the immunophenotype and pattern of cytokine production by distinct subpopulations of normal human peripheral blood MHC II+/lineage- cells. Clin Exp Immunol. 1999; 118:392-401.

21. Jegalian AG, Buxbaum NP, Facchetti F, Raffeld M, Pittaluga S, Wayne AS, Jaffe ES. Blastic plasmacytoid dendritic cell neoplasm in children: diagnostic features and clinical implications. Haematologica. 2010; 95:1873-1879.

22. Feuillard J, Jacob MC, Valensi F, Maynadie M, Gressin R, Chaperot L, Arnoulet C, Brignole-Baudouin F, Drenou B, Duchayne E, Falkenrodt A, Garand R, Homolle E, Husson B, Kuhlein E, Le Calvez G, et al. Clinical and biologic features of CD4(+)CD56(+) malignancies. Blood. 2002; 99:1556-1563.

23. Vermi W, Facchetti F, Rosati S, Vergoni F, Rossi E, Festa S, Remotti D, Grigolato P, Massarelli G, Frizzera G. Nodal and extranodal tumor-forming accumulation of plasmacytoid monocytes/interferon-producing cells associated with myeloid disorders. Am J Surg Pathol. 2004; 28:585-595.

24. Mohty M, Jarrossay D, Lafage-Pochitaloff M, Zandotti C, Briere F, de Lamballeri XN, Isnardon D, Sainty D, Olive D, Gaugler B. Circulating blood dendritic cells from myeloid leukemia patients display quantitative and cytogenetic abnormalities as well as functional impairment. Blood. 2001; 98:3750-3756.

25. Petrella $\mathrm{T}$, Bagot M, Willemze R, Beylot-Barry M, Vergier B, Delaunay M, Meijer CJ, Courville P, Joly P, Grange F, De Muret A, Machet L, Dompmartin A, Bosq J, Durlach A, Bernard P, et al. Blastic NK-cell lymphomas (agranular CD4+CD56+ hematodermic neoplasms): a review. Am J Clin Pathol. 2005; 123:662-675.

26. Roos-Weil D, Dietrich S, Boumendil A, Polge E, Bron D, Carreras E, Iriondo Atienza A, Arcese W, Beelen DW, Cornelissen JJ, Kroger N, Milone G, Rossi G, Jardin F, Peters C, Rocha V, et al. Stem cell transplantation can provide durable disease control in blastic plasmacytoid dendritic cell neoplasm: a retrospective study from the European Group for Blood and Marrow Transplantation. Blood. 2013; 121:440-446.

27. Terpos E, Katodritou E, Roussou M, Pouli A, Michalis E, Delimpasi S, Parcharidou A, Kartasis Z, Zomas A, Symeonidis A, Viniou NA, Anagnostopoulos N, Economopoulos T, Zervas K, Dimopoulos MA. High serum lactate dehydrogenase adds prognostic value to the international myeloma staging system even in the era of novel agents. Eur J Haematol. 2010; 85:114-119.

28. Swan F Jr., Velasquez WS, Tucker S, Redman JR, Rodriguez MA, McLaughlin P. Hagemeister FB and Cabanillas F. A new serologic staging system for large-cell lymphomas based on initial beta 2-microglobulin and lactate dehydrogenase levels. J Clin Oncol. 1989; 7:1518-1527.

29. Frankel AE, Woo JH, Ahn C, Pemmaraju N, Medeiros BC, Carraway HE, Frankfurt O, Forman SJ, Yang XA, Konopleva M, Garnache-Ottou F, Angelot-Delettre F, Brooks C, Szarek M, Rowinsky E. Activity of SL-401, a targeted therapy directed to interleukin-3 receptor, in blastic plasmacytoid dendritic cell neoplasm patients. Blood. 2014; 124:385-392.

30. Munoz L, Nomdedeu JF, Lopez O, Carnicer MJ, Bellido M, Aventin A, Brunet S, Sierra J. Interleukin-3 receptor alpha chain (CD123) is widely expressed in hematologic malignancies. Haematologica. 2001; 86:1261-1269.

31. Ribera JM, Oriol A, Morgades M, Montesinos P, Sarra J, Gonzalez-Campos J, Brunet S, Tormo M, FernandezAbellan P, Guardia R, Bernal MT, Esteve J, Barba P, 
Moreno MJ, Bermudez A, Cladera A, et al. Treatment of high-risk Philadelphia chromosome-negative acute lymphoblastic leukemia in adolescents and adults according to early cytologic response and minimal residual disease after consolidation assessed by flow cytometry: final results of the PETHEMA ALL-AR-03 trial. J Clin Oncol. 2014; 32:1595-1604.
32. van Dongen JJ, Lhermitte L, Bottcher S, Almeida J, van der Velden VH, Flores-Montero J, Rawstron A, Asnafi V, Lecrevisse Q, Lucio P, Mejstrikova E, Szczepanski T, Kalina T, de Tute R, Bruggemann M, Sedek L, et al. EuroFlow antibody panels for standardized n-dimensional flow cytometric immunophenotyping of normal, reactive and malignant leukocytes. Leukemia. 2012; 26:1908-1975. 